This is an Accepted Manuscript of an article published by Taylor \& Francis Group in Women's History Review on 20 May 2018, available online: http://www.tandfonline.com/10.1080/09612025.2018.1472897

\title{
Isolated and dependent: women and children in high-rise social housing in post-war Glasgow ${ }^{1}$
}

\author{
Lynn Abrams, Linda Fleming, Barry Hazley, Valerie Wright, Ade Kearns
}

University of Glasgow

\section{$\underline{\text { Introduction }}$}

In the late 1960s when Pearl Jephcott conducted her groundbreaking research into high rise living in Glasgow, published as Homes in High Flats in 1971, the particular needs of women and children in this new style of housing were already on the agenda of social scientists and feminist researchers. ${ }^{2}$ For Jephcott, who had made her name working closely with urban working-class communities in London, the concerns of women and especially young mothers, were central to her research agenda. In Glasgow, Jephcott was conscious of the networks that existed in long standing working-class communities that provided companionship and support to women; by contrast, on the new high rise estates she keenly observed the isolation of young mothers and the lack of facilities for young children. In the post-war settlement the family was positioned at the heart of social regeneration and reconstruction and improved housing was one of the main conduits for attempts to regenerate communities, unsurprising given the execrable housing conditions in many post war urban areas and the desperate need for improvements.

In Glasgow, where housing for the urban poor was amongst the worst in Britain, characterised by severe overcrowding, structural deficiencies and the absence of basic necessities such as indoor WCs, the high rise block was identified as a solution to the intractable problem of rehousing thousands of tenants. By 1971, Glasgow had more than 200 tower blocks containing almost 21,000 flats and providing homes to 50,000 people. ${ }^{3}$ In the $1960 \mathrm{~s}$, these flats were thought of as providing a perfect combination of cosy, nuclear-family living with brave new modernity and they were heralded as the solution to many health and social problems that commonly affected working-class people's lives. By the time Jephcott arrived in the city to conduct her research on young people's leisure (The Time of One's Own project discussed by Susan Batchelor elsewhere in this volume), the tower block was an established feature of the Glasgow skyline and was already the object of public debate about the utility of this particular housing model for community cohesion and social wellbeing. Jephcott's intervention in that debate focused primarily on what she described as 'the human problems' contingent on the decision to build high.

This article draws primarily on evidence collected by Jephcott's research into the experience of living in high flats between 1966 and 1969, a moment in time which captured some of the earliest responses to high flat living in the UK. ${ }^{4}$ It is supplemented by case study material drawn from the investigations of the Royal Scottish Society for the Prevention of Cruelty to Children (RSSPCC), whose Women Visitors worked actively with families suffering poverty and family breakdown. ${ }^{5}$ We have focused on the cases where high flats were identified. The RSSPCC case files have the benefit of offering a more in-depth observation of a family's circumstances (albeit from the perspective of a social welfare agency) and, in some cases where ongoing support was provided, give an insight into longer term family dynamics as opposed to the one-off snapshot elicited by Jephcott's questionnaires which consisted of a few pages of usually short responses to closed questions. ${ }^{6}$ Together, these sources provide both high level and intimate detail concerning the relationship between housing and social outcomes, in this case for women and children. Although Jephcott did not, as far as we know, make 
contact with the RSSPCC she was, like a number of her contemporaries, alert to the very particular difficulties faced by mothers of young children in this period who were defined primarily as housewives and carers in popular discourse and as dependents by the welfare system at a time when the home was still conceptualised as central to women's lives. ${ }^{7}$ Upon being rehoused to a high flat these difficulties, practical and psychological, were amplified. Jephcott was attuned to the effects of the combination of an absence of points of casual contact and very limited resources (both financial and cultural) to expand personal horizons, which worked to consign some women to an isolated existence. An easy to clean modern flat did not compensate when a woman had no external life and no money. The high flat itself was not the sole cause of their problems - indeed many appreciated the material comforts of their modern homes - but, in this particular era and social context , housing design contributed to social isolation and for some, relocation coupled with higher housing costs exposed women's economic dependence. In revealing the association between high-rise housing and poor outcomes for women, Jephcott was at the forefront of research trends that were to question the appropriateness of high-rise housing for young families, a question that continues to interest researchers today. In what follows we revisit Jephcott's research in order to interrogate more deeply than she managed to do, the factors that impacted on women's wellbeing in high flats. By focusing in greater depth on the qualitative free comments offered by tenants to Jephcott's researchers, our work offers new insight into the contemporary subjectivities engendered by high flat living, especially in women. The proposition that high flats were not suited to the welfare needs of families with young children is not new of course and in fact, as a proportion of households, those with young children were in the minority of high flat tenants.. ${ }^{8}$ But Jephcott's findings, based on market-research style interviews with 1000 high flat tenants, suggest to us that there were significant divergent experiences amongst women dependent upon a number of variables: distance moved from previous housing; location of new high rise home (central location or peripheral) and life stage. We argue that economic stability of the household should be included in this list, a crucial factor when added to the social dislocation caused by rehousing to a high flat as the investigations by the RSSPCC highlighted.

This article interrogates two connected factors, social isolation and economic dependence, which characterised the experience of many women who were rehoused to high flats in the postwar decades. Firstly we take some time to frame the discussion by outlining the particular context that pertained in Glasgow of provision of modern family homes in high density multi-storey social housing and we outline the arguments made by contemporary researchers regarding working-class women's subsequent housing experiences in the postwar era. Secondly we explain how, for some women, despite offering material improvements and greater privacy, the move to the high flats separated and isolated them from social networks and opportunities for economic independence. And finally we explore how economic instability produced women's dependence (on men and on the state) and further enshrined their isolation within the home. Thus we close the circle that Jephcott left open. She asserted that high rise housing had socially negative consequences for women and children. We do not disagree but argue that in the particular context of the postwar settlement, women's financial and welfare dependence on top of their particular housing circumstances in high rise flats constrained their opportunities rather than producing contentment thereby demonstrating the value of revisiting social research data. In the contemporary world, the relationship between housing quality and design, financial resilience and social wellbeing is more readily apparent and better understood. In the 1960s Jephcott made the link, like many others, between housing and social wellbeing but her focus on the 'attrition of social life' in high-rise estates blinded her to the multiple and interconnected factors that caused women in particular to be disadvantaged within this particular form of housing. 


\section{Modern high-rise domesticity}

In the 1960s, the new high flats were thought to provide a perfect combination of cosy, nuclear-family living with brave new modernity and the decision to house so many families in high flats was aggressively defended. The promotional film - Mungo's Medals - produced by Glasgow Corporation in 1961, trumpeted the benefits of this modern style of living for those who were being rehoused from tenement slum housing. The Moss Heights development was Glasgow's first high-rise experiment and was completed in 1953. It consisted of three blocks of ten storeys, a modest height compared to what would follow, and was located on high ground to the south-west of the city centre. This housing scheme was presented as the nuclear family's dream. Flats had a kitchen with all modern conveniences for the woman of the house, a living room with space for the family to relax together (no recessed beds in the kitchen here as was common in tenement flats - a common cause of outrage on the part of those who believed overcrowding caused immorality) and a balcony - or 'verandah' as it is called in Glasgow - from where the mother could keep an eye on her children playing on the common ground beneath the block. The commentary that accompanied footage of a young family enjoying their new home sought to amplify the health and psychological benefits for families of the new housing:

Behind another door are those young parents who have spent sleepless nights worried about the health of their children. In this house, with all its modern amenities, the mother can care for her bairns as she has always wanted to. She is no longer haunted by the fear that they have wandered away to some traffic-filled streets or that they are breathing germs of disease in some refuse filled back court. When they come into this house from play she has hot water on tap to wash away the healthy dirt they have collected. Now there is room to live, no longer with all their possessions cluttered together in one apartment. Later the children will go to bed, in their own rooms. By day, from her Moss Heights balcony, the mother can see and hear her children at play. ${ }^{9}$

The move to a modern flat with modern facilities - indoor WC and bath, central heating and hot water and in the case of Moss Heights, a heated towel rail and a double sink with a wringer for the laundry could not have come soon enough for many families living in overcrowded, substandard and often condemned accommodation. But it also came at a high price - both metaphorically and literally. While Moss Heights tenants may have been able to manage the average 53 per cent increase in rent owing to the greater preponderance of the skilled and non manual occupations represented here, in other later and less prestigious housing schemes the average 42 per cent increase in living costs was coupled with patterns of irregular male employment which could push households into debt. ${ }^{10}$ Added to this, the experience of many women of managing everyday life in a high rise flat with young children was frustrating, often lonely and unsupported. Upon being rehoused to a new high rise flat, initial euphoria at the material comforts could turn into disillusionment as the reality of living high and in some cases on estates located some miles from the city centre and lacking basic amenities was experienced on a day-to-day level reinforcing women's dependence on men, who were still designated as primary breadwinners by the state and social services. ${ }^{11}$ Those who took it upon themselves to intervene (statutory agencies and charities) - in the interests of family stability and child welfare - tended to reinforce the inequalities of power within working-class families whereas attempts to bolster the capacity of women, especially mothers of young children (Jephcott's preferred approach), as Hazley et al demonstrate in their article in this collection, largely foundered in the absence of sustained support. 
Contemporary social observers and subsequent historians have recognised the phenomenon of female isolation and dependency contingent upon rehousing in the post war era. Following Young and Willmott's classic 1957 study of the working-class community of Bethnal Green and the consequences of its move to Greenleigh in Essex, and Hilda Jennings' study of Barton Hill in Bristol a few years later, the centrality of generations of the maternal line in cementing community cohesion has been influential in framing understandings of the working-class community and women's place within it despite more recent critiques. ${ }^{12}$ Independence in these communities was understood and practiced as self-reliance within the kin group, many of whose members lived in close proximity. In these long-established and people-centred (as opposed to home-centred) communities, married women may have felt stifled at times by the ties of kinship and the constant presence of relatives. Yet at the same time the proximity of mothers and grandmothers and the security of the street whereby 'the family feeling of the home was extended to neighbours' meant that married women could undertake paid work knowing they had the practical support of mothers and mothers-in-law. ${ }^{13}$

In Scotland's urban centres the street, which looms so large in analyses of English working-class communities, is replaced by the tenement and the shared close and backcourt. The Victorian tenements that housed the majority of working-class city dwellers in Scotland were up to five storeys and contained several flats on each floor. By the end of the nineteenth century, many spacious mansion flats and townhouses had been subdivided with tens of thousands of families in Glasgow alone living in just one room and homes became run down and seriously overcrowded. ${ }^{14}$ One-room flats were also purpose built in many tenements. As late as 1951 these small homes housed a quarter of the Scottish population. ${ }^{15}$ These urban neighbourhoods have often been lauded for facilitating strong female networks on account of the close proximity of families, the need for women to organise the cleaning of common areas and take turns using the back court on washdays, and thereby providing opportunities for stair-head gossiping and sociability. ${ }^{16}$ Nevertheless it has also been pointed out that domestic work in Victorian tenements was heavier and harder for Scottish women than their English counterparts on account of the stairs and shared landings and far from cementing female bonds, was a daily source of irritation and conflict. In other words, living in tenements got on a lot of women's nerves. ${ }^{17}$ As in England, there were some advantages for women, especially those with young children, of living cheek by jowl with extended family members and other families in similar circumstances where local amenities such as small shops provided a point of contact though it is unclear if employment for married women was facilitated in the urban Scottish context given that respectability was often predicated on married women staying at home in the west of Scotland and the employment market in Scotland as a whole remained segregated by gender until the 1980s. ${ }^{18}$

In the English studies, relocation and rehousing disrupted these support networks with varied results. In Barton Hill, Bristol, some young mothers gave up paid employment when they moved house on account of the absence of child minding and increased distance from work. ${ }^{19}$ Likewise, in Greenleigh Young and Willmott argued that the home (rather than the extended kin network) became the focus of young women's lives. ${ }^{20}$ In the Scottish context, the absence of local studies of the extensive relocation that occurred in the post-war decades makes it difficult to see whether a similar pattern pertained here. We might surmise that rehousing, especially to an estate on the periphery of a city with few employment opportunities for women and the difficulties and expense of travel to work elsewhere, must have impinged on women's ability to earn wages. ${ }^{21}$ Certainly on the peripheral estates around Glasgow - Castlemilk, Drumchapel, Easterhouse and Possilpark - work for women was not only hard to come by but hard to reach. In 1969 The Herald reported from Easterhouse on the 'increasing number of housewives who want to work' but there was none available locally. ${ }^{22}$ 
Feminist Hannah Gavron was clear about the plight of working-class wives in the 1960s. In her 1966 study The Captive Wife, which examined the experiences of working and middle- class mothers in London, she countered the dominant medical and popular discourse which identified middle-class women as suffering from 'suburban neurosis' as a result of their isolation and their captivity in a world of privacy and domesticity. ${ }^{23}$ Gavron showed that whereas for middle-class women, education, geographical mobility and work provided a strategy for independence, this was not the case for many working class-women. Women in this socio-economic group could easily become trapped in poverty, dependent on male partners whose employment was not always stable and on top of that, might be relocated to new housing where they were often some distance from family and kin networks.

Gavron's key finding in respect of working-class women concerned the shift they experienced from an extended family and neighbourhood-focused life which characterised their mothers' experience, to a nuclear family home-centred life. This was a younger generation for whom neighbours and 'the street' were less significant; the centre of their world was the home where they were lonely and bored having given up work on the birth of their first child. ${ }^{24}$ And 'from the point of view of the mother' concluded Gavron, 'this means an almost complete submersion into domesticity, with perhaps less opportunity for escape than her mother enjoyed. ${ }^{25}$ In these circumstances, she rightly concluded that the quality of housing was key to the young mother's quality of life and sense of wellbeing. In the absence of street life and what she describes as a 'woman's world' and without other forms of sociability such as in the workplace, working-class women became isolated, completely mother-focused and yet often housed in circumstances inappropriate for small children leading to frustration and loneliness. ${ }^{26}$

In Glasgow, all of the issues identified by Gavron are writ large with high-rise flats arguably exacerbating women's isolation in a physical sense, a conclusion reached by Jephcott who was familiar with Gavron's work. With the exception of a few architect-designed blocks, the vast majority were erected quickly and economically by commercial contractors. ${ }^{27}$ These were engineered (in precast concrete) and from the outside could be seen as brutal, faceless and abstract giving 'no concession to an architecture of domesticity', lacking spaces for spontaneous sociability and privileging privacy. ${ }^{28}$ Inside, however, these new homes seemed bright and modern and ideally suited to nuclear family living. They were invariably better equipped than tenants' previous homes in terms of modern conveniences: electric heating and hot water on tap, well appointed kitchens, and of course private WCs and baths which many had had to share in their previous residences. They often had large windows with wonderful views, balconies and easy to clean surfaces. There was no filthy coal fire to maintain, a drying room for the laundry and separate living and sleeping accommodation. These were homes ostensibly designed with the working-class wife and mother in mind with all the mod cons to make her life easier.

But the reform of housing is so often seen in terms of fixtures and appliances rather than the fundamental issues that determine wellbeing such as the financial costs, the organisation of domestic labour and the care of children of all ages.$^{29}$ Women were still the primary carers, homemakers and sustainers of everyday life and it was certainly they who bore the brunt of poor design and quality and were more likely to became trapped in the closed-off high rise flat. Over the years, poorly fitting windows, insufficient soundproofing, damp walls and lifts continually malfunctioning were significant flaws and in many buildings impacted on women's everyday lives and wellbeing in profound ways. But above and beyond the material discomforts, evidence from Glasgow indicates how the ideal of the single-breadwinner, nuclear family enshrined within the post-war welfare settlement often came under extra strain in the particular environment of the high flat. In other words, high flat living did not cause the problems experienced by women but it did exacerbate them Whereas 
earlier studies showed how the benefits of a modern new house and a healthier environment eventually outweighed people's negative feelings about moving away from former communities, in the case of the high rises the material benefits of the new home were not always sufficient to counter the problems caused by this new design for living. Moreover, issues which the postwar welfare state sought to address such as poverty, health inequalities and greater access to employment opportunities were so gendered to put social pressures on women to give themselves over to the home and care of the family. The high rise did little to help women in these circumstances and a great deal to increase personal feelings of inadequacy and failure to live up to domestic ideals.

\section{Isolation}

Given the emphasis in so many community studies on the importance of social networks to women's sense of wellbeing, evidence that suggests women felt isolated in their new homes needs to be taken seriously. What is most revealing in Jephcott's study is the gap between what people directly expressed about the 'physical environment' of the housing - easily depicted as beneficial - and what they actually felt about these flats as homes in the wider context of their social lives. Clearly, in the first flushes of enthusiasm for the high rises there were real material issues that affected people's sense of wellbeing. The 'physical character' of new flats was of an air of 'cleanliness, brightness, airiness and modernity'. Comments such as 'I love my house. I just love everything in it. The surroundings are lovely and the central heating is marvellous' are not atypical. 'I like it - no dislikes. I like the central heating (underfloor) plus the kitchenette worktops and I like the layout of the kitchenette' remarked a female resident of Castlemilk, a peripheral estate to the south of the city. ${ }^{30}$ Indeed Jephcott herself noted that the majority of people questioned said something like 'we are very well satisfied' or 'we seem to be happy enough'. ${ }^{31}$ Material attractions were still high on tenants' agendas when they were questioned as most had only lived there a short time. Having a private bathroom was still regarded a luxury; the convenience of the electric heating was mentioned; and in cold, wet and windy Glasgow it was important to have a 'snug' place to live. ${ }^{32}$ Tenants did not seem to mind being so high up.

In contrast to residential satisfaction, wellbeing was not solely contingent upon having a modern flat with all mod cons. Wellbeing for women was predicated on a complex mix of factors, which in part had to do with the housing environment (which included the exterior landscape), but was also related to a more general sense of what one needed to live a contented and socially integrated life. Jephcott herself intuitively understood how people's interactions on a quotidian level affected their state of wellbeing. She remarked:

A high flat drastically reduces the visual signals that, trivial in themselves, help people to get to know about each other. There is no front window where new curtains, Mother's Day daffodils, or a schoolboy's model plane tell their day to day story about the people inside. With no smoke from the chimney, no line of washing being taken in and no windows lighting up, neighbours do not know if the place is empty or crammed. Nor can happenings outside the block be related to a specific household... ${ }^{33}$

In these circumstances, mundane, everyday irritations could easily trump the convenience of central heating and result in feelings of isolation for any high-rise resident. Poor design and build quality, the unreliable lifts and poor maintenance were underlying anxieties for all categories of respondent. But for women who, we should remember, spent most of their time at home there were added frustrations. A 1965 report by the Glasgow Chamber of Commerce had already identified two key problems which primarily affected women: the lack of laundry provision and the absence of play facilities for 
children. ${ }^{34}$ The difficulty in getting the washing dry when drying rooms were damp or insecure or the drying cupboard was too expensive and use of the balcony for laundry drying was not permitted, were everyday frustrations that sapped energy and fostered demoralisation. ${ }^{35}$ On peripheral estates in particular (though not exclusively) in the absence of chance interactions with neighbours - no gardens or back courts or streets in the conventional sense, just exposed, inhospitable landscaping around the blocks sand few facilities nearby such as shops, health centres or even schools in the early years of such high rises - women acknowledged that the high rise fostered isolation, as this young woman explained: 'I discovered that meeting people in a multi-storey block is not easy. Each house is rather like a warm, comfortable isolated cell... I used to go out to empty some rubbish in the hope of seeing some other living soul but invariably there was just no one... ${ }^{16}$

Indeed appreciation of the flat was often outweighed by more psychosocial anxieties. Mrs S. who was one of the 36 per cent of respondents who had moved less than a mile - in her case just a few streets from a condemned single-end to a three-apartment flat on the second floor of Waddel Court in the Gorbals-Hutchesontown estate with her husband and four children under the age of 10, expressed this well when asked by Jephcott's researcher her views on her new home. ${ }^{37}$

I like the house. I have more room and the 2 verandahs are good for putting the baby out on. I find the bedrooms damp. Kitchenette is too narrow no use for giving the children their food.

I don't like the long corridors too many doors on each landing. Makes a lot of cleaning. There are 3 dryers on each landing and they haven't worked for 3 yrs. This is caused by strangers coming up and breaking into them and stealing the money. Would like my house much better if you could just take it and put it somewhere else. I am sorry I have come to the multi-storey flats. I find them no use with children. No division on the verandahs and children run from one end to the other. Much too lonely, never see anybody for weeks. Can go in and out and never meet anybody. ${ }^{38}$

Such seemingly contradictory views (appreciation of the house but frustration with the broader environment) are not uncommon although in Jephcott's sample in this particular estate there were few families with young children. And it was older respondents who were more likely to comment on feeling lonely. A closer analysis of the responses elicited by Jephcott's team indicates more divergent opinions, with some differences between those who had been rehoused to high rise estates adjacent to their previous homes and those who had moved to the peripheral schemes. For instance, high rise tenants in the Gorbals and in some other city-centre estates such as Wyndford had typically moved only a short distance from their previous homes whereas those who moved to peripheral schemes such as Castlemilk four miles from the city centre and on a hilly site, found themselves some miles from social networks and even everyday facilities such as shops and health provision. Jephcott's team chose Castlemilk as one of five selected estates for more sustained study. Situated on the edge of an established low rise estate, the five 19-storey blocks on Mitchellhill stood adjacent to farm and woodland and were a 20 minute walk away from local amenities.$^{39}$ Here, the very particular strains on women with young children were clearly articulated by this 28 -year old living with her husband and three children under four years old in a flat in Castlemilk. The family had moved from the Gallowgate in the city centre where they had been homeless and lodging with family.

I can't let the children out to play - my daughter has never been out to play since we came up here. She won't use the lift as she's scared and there's no place for her to play outside except 
for the front of the block and she's afraid of the motor cars. We use the verandah for her to play...Shops are much too far away and they're all uphill; coming back with heavy shopping, the wee one and the toddlers I'm exhausted by half way...I hardly ever see my five sisters as much as I used to. The travelling is too much by the time my husband comes in at night and during the day it's too much with the children and it's the same for my sisters...You speak to people more when you do meet them as you're so unused to having people to speak to. I think it does make you mix more readily. I'm quite happy with the house but there are a lot of things against it for the children. I don't really feel they get out enough, I think it holds them back. I've noticed relatives' children seem farther advanced and she (my daughter) seems more old fashioned about the house. ${ }^{40}$

Isolation was a new experience for many women who had been used to overcrowding and proximity to kin and it was experienced along a spectrum, some extolling the new privacy they enjoyed in their new flats and others bemoaning the loneliness.

One of the benefits of the massive rehousing programme undertaken in Glasgow was said to be the privacy afforded to those who had hitherto shared cramped accommodation or lodgings. It was a proud boast of the Corporation in the film Mungo's Medals already referred to above, that privacy could now be achieved. As the camera follows a single middle-aged woman returning from work to her flat in a medium high rise block the commentary informs us:

for the first time in all her adult life she is really coming home - not to a noisy corner in some other person's house, but to her own home where she can shut out the world; where she can sit and read, watch the television, listen to her record player, or just close her eyes and enjoy being alone [emphasis added] ${ }^{41}$

Even Jephcott was surprised that 'an unexpectedly large number of tenants stressed the value of the privacy the flats afforded'. Mrs H., married with two school-age children and in part time work who, like the young mother quoted above, also lived in distant Castlemilk, appreciated the privacy. 'I like being up 18 stairs, you can see all over Glasgow. It's quiet, you never see your neighbours - there is so many families up here you'd think you'd be clashing into one another but it's nice, you never see a soul. ${ }^{42}$ Similarly, 22 year old Mrs W. commented that 'When you live in a block type house you see your neighbours. Here you don't know them. But I like that. ${ }^{43}$ The flat in a high rise enabled privacy like no other form of home if that is what you desired. And indeed interviews with working married and single women reveal much higher satisfaction levels than with those not in paid work. A married resident of Mitchellhill, Castlemilk with a toddler (who was looked after by her mother when she was working in the city centre) acknowledged if she had not been in work outside the home, loneliness would be a problem: 'if you go out you meet someone. Think they'd be lonely if they were alone or old living in the block. ${ }^{44}$

However, for those women who were not in paid employment outside the home - and at least half of the women interviewed in the study came into this category - a tension between loneliness and privacy was often articulated which reflects the changing culture of family and community in this period. ${ }^{45}$ By the 1960 s it was widely accepted that family privacy trumped neighbourliness. ${ }^{46}$ Socalled 'active neighbouring' was replaced by 'keeping ones distance'. ${ }^{47}$ It is also clear that the enforced neighbourliness of the tenement where women were compelled to accommodate one another's needs and uses of shared facilities and to constantly negotiate over the cleaning of communal areas, was something that many women looked forward to escaping. Women themselves complained of it - 
squabbles over noise and mess in closes, having to share inadequate back-court laundry facilities, being able to hear every intimate movement made by neighbours and knowing they could hear you, what Jephcott aptly describes as 'inescapable togetherness'. ${ }^{48}$ Promoters of high rises sold the idea or fantasy of privacy which must have appealed initially. In 1965, an item on social conditions in high flats in the Glasgow Chamber of Commerce journal stated with confidence: 'There was not the same feeling that one's neighbours knew all about one's affairs such as exists in the old overcrowded tenement type of district and a number of occupiers interviewed welcomed the increased privacy. ${ }^{, 49}$ This was rather a simplistic and misleading representation of course. In most blocks women were still obliged to organise communal cleaning of common areas and in some, community attempts to manage the block to maintain respectability imposed expectations on tenants who may well have been resentful at having to cooperate. Of course, one could yearn for privacy in such high-density areas without desiring or anticipating loneliness or isolation. But isolation was often what one felt on a new estate, several floors up, with no transport or means of contact with the outside world. Only a third of households in Jephcott's study had telephones. Very few women could drive or had access to cars only 22 per cent of households in the survey had a car - and on peripheral schemes public transport was frequently poor ${ }^{50}$ In Castlemilk, the hilly terrain on which the blocks were sited meant a difficult journey to the shops a 20-minute walk away, especially for the infirm or those with small children. ${ }^{51}$ 'When I wanted to do some shopping', wrote one young mother:

I would put both children in the pram, go out into the landing and press the lift button to descend. The lift seemed to be constantly out of order ... so as often as not I had to push the pram down three flights of stairs. I shudder to think how the poor mothers on the eighteenth floor managed. ...Having done my shopping I would return, pull the pram up all the stairs again and back into the flat. All of which would be accomplished without my having glimpsed a neighbour, far less having a word with one. ${ }^{52}$

Castlemilk was especially isolating in the early years on account of the absence of shops and other facilities, a fact picked up by Valerie Sommerville, one of Jephcott's student researchers $n$ an ethnographic walkabout.

The nearest shops are 13 minutes walk downhill - therefore back uphill with shopping to carry. Even then there is only a butcher's, grocer's, post-office etc. the main shopping centre is nearly two miles away. There is no filling station or launderette near. Various people with big laundry bags were about, obviously having to go to the launderette by car. Some washing was hanging about on the balconies, but these were obviously not big enough for a family wash....There were two or three mobile vans in the area, which the housewives said they found very convenient. ${ }^{53}$

Jephcott was conscious of the networks that existed in long standing working-class communities that often provided companionship and support, especially to mothers of young children.In one housing scheme consisting of three 21-storey blocks, discussion groups that Jephcott's team held with mothers identified a good degree of isolation amongst this group and concern about their children's development, but efforts to organise a play group in another part of the city - Royston - initiated and supported by the High Flats researchers failed to thrive in the longer term on account of the fact that during the day most of the women returned to where their mothers lived in the city which, in many cases was not far away. ${ }^{54} \mathrm{Mrs} \mathrm{O}$. who had moved with her husband and two young children from a single-end apartment in Bridgeton in Glasgow's east end to a flat in Cranhill, just a mile or so away, told the researcher: 'I don't bother going out much. I can get to my mother's just as quickly from here 
as from my old place. I spend a lot of time at my mother's. Was there all day today. ${ }^{55}$ But this meant she did not develop social relationships with other women locally.

In the 1960s the term 'high flats neurosis' was coined to describe the anxiety associated with high flats living, especially amongst young mothers. D.M.Fanning, writing in the British Medical Journal in 1967, showed that the incidence of psychoneurotic disorders was three times higher for women in their twenties living in flats compared to those living in houses ${ }^{56}$ She put this down to boredom, confinement (especially for those with young children who could not be allowed out in the absence of suitable play facilities) and little contact with neighbours. Indeed, she suggested that the situation was worse for women in flats because here children did not provide a natural contact point amongst young mothers as they would on a low rise housing estate, a point also picked up by Jephcott who championed play facilities as one means of ameliorating both children's and mother's isolation. Gittus' 1976 examination of families with children under the age of five living in high and low rise flats on Tyneside observed that flat-living - whether high or low - seemed to be associated with nervous strain. 65 per cent of mothers living above the 6th floor in one development reported they were more nervy, experienced loneliness, and just felt 'worse' than they had been in their previous homes whilst those rehoused to maisonettes and houses reported beneficial effects for themselves and their children. ${ }^{57} \mathrm{In}$ Gittus' study, the absence of street life, points of social contact such as clinics and shops, and social and familial networks andthe sense of being trapped in a flat coupled with the absence of suitable play areas lent weight to the conclusion that high rises were not suitable for young families and were a factor in these women's isolation and vulnerability. Aware of the link between housing design, relocation and so-called 'neurosis', Jephcott wrote to the Chief Medical Officer of Health to enquire about research findings linking housing and health and he replied assuming she was referring to 'flat neurosis'. ${ }^{58}$ These women suffered from 'nerves' not solely because of boredom and the chains of domesticity as had been posited in studies of women in suburban contexts, but because of the stress of having to cope in a very difficult situation: young children who they were afraid to allow out (or even onto the veranda) because there was nowhere safe for them to play; not enough money coming in; debts; isolation from friends and family and few support structures such as health clinics, playgroups or sources of formal or informal support in the face of such trials. Two of the largest estates in Glasgow, Red Road and Castlemilk, had no children's playgounds within a half a mile radius, no nursery school or child welfare clinic, antenatal classes or mothercraft centre. ${ }^{59}$

\section{$\underline{\text { Dependence }}$}

Jephcott's concerns about the wellbeing of families and children in high flats were largely reported in terms of their social welfare. She devised ingenious research methods to reveal the extent of social contact (recording, for instance, the last person met by questionnaire respondents and asking questions about means of transport and communication, lift waiting times and social life). Financial welfare featured less prominently in her work despite the context of the post war welfare state which had positioned women as dependents on men who were still designated as primary breadwinners (and as holders of tenancies) by the state and social services. ${ }^{60}$ So for evidence of the relationship between women's isolation, economic hardship and dependence on welfare support in the context of being rehoused to the high flats we need to turn to another source: the family case files written by the women visitors of the RSSPCC. These provide more in-depth information than Jephcott was able to offer with her large-scale light-touch sampling of households. In the 1960s and 70s the work of the Women Visitors, acting as pseudo-social workers before the 1968 Social Work Act (Scotland), offers some insight into the strains on women, though by no means were a majority of their cases located in high flats. 
Although Jephcott recorded the cost of living in the high flats she was more interested in cultural and social than economic poverty evidenced by the kinds of connections she made - with health workers, planners and play organisations. ${ }^{61}$ The High Flats project archive contains no evidence of engagement with statutory agencies such as the city social work department but Jephcott can hardly have been unaware of the strains on some families which, in the most desperate cases, necessitated the intervention of external agencies. High flat living not only exacerbated the negative elements of the increasingly home-centred existence experienced by many families in this period; it was also expensive and isolation made the financial shock many experienced hard to overcome. In many cases, rents doubled and in some cases quadrupled on the move to high flats. Whereas 61 per cent of households in Jephcott's sample paid rent and rates of under $£ 4$ a month in their previous homes, in the high flats 84 per cent paid between $£ 6$ and $£ 10$, a significant increase. In addition, more than half reported utility costs as the same or more expensive. ${ }^{62}$ Average monthly manual worker wages for men at this time were around $£ 30$ meaning that rent could account for one third of income. ${ }^{63} \mathrm{Jephcott}$ would not have been unaware of cases such as family $\mathrm{G}$ - husband, wife and three children - who moved from a room and kitchen tenement flat in Springburn to a 4-apartment first floor flat in the new Moss Heights development. Mr G was a semi-skilled manual worker, Mrs G. was a housewife. Their monthly rent increased overnight from $£ 2-11-8$ to $£ 10-18-9 .{ }^{64}$ Coupled with this were electricity costs in those homes where all heating and cooking depended on this source of energy. ${ }^{65}$ These could be very high for families with babies and young children and for older residents, both of whom would be likely to be at home all day during a cold Scottish winter. On top of the increased rent and higher utility charges were, for a number of families, hire purchase payments made on furnishings bought to fill all this unaccustomed space. Young couples in particular, it was thought, were prone to become enmeshed in debt and according to the Royal Scottish Society for the Prevention of Cruelty to Children in 1963, 'Wives entering HP agreements outwith the knowledge of their husbands is also a cause, on occasion, of domestic trouble', whilst also admitting that for some the resort to hire purchase was unavoidable and was used for essentials, even children's clothing. ${ }^{66}$

Social and charity workers, on the other hand, were cognisant of the difficulties caused by the combination of insufficient income, high living costs and isolation from support networks by virtue of their intimate and sometimes ongoing contacts with families in distress. At this time it was the RSSPCC who provided practical help and advice to families who were in financial and other trouble, liaising with creditors, sourcing loans, managing debt repayments and giving advice on household and relationship management, mainly to women. ${ }^{67}$ Money problems were often both the cause of and a symptom of alleged family instability. In a 1972 study of the RSSPCC's work with 'neglected families' across Scotland it was calculated that in 41 per cent of the 475 cases examined, the initial approach to the organisation was on account of financial problems; housing and health issues made up another 13 per cent. Indeed indebtedness was endemic and in 60 per cent of cases investigated in the RSSPCC study the family's income was below what the Ministry of Social Security calculated was minimum need. Another 22 per cent had income at minimum need levels but no more. Over half were in debt, owing rent, utility bills and loan or HP agreements. ${ }^{68}$ In 40 per cent of cases investigated between 1945 and 1960 the father was unemployed and a further 11 per cent were in casual employment and in the period 1960-75 all the men who were in work in families inspected by the organisation were in manual employment. ${ }^{69}$

In 1969 the RSSPCC visited the home of a family consisting of the parents and 5 children, 3 of them pre-school age, living in a 4 apartment high flat. The mother had sought advice from the organisation as the family was about to be evicted. The father was unemployed having left his work on a 
construction site in order to look after the other children when his wife was admitted to the maternity hospital. He was in receipt of £13-7s National Insurance and £2-18s Family Allowance. They were in rent arrears to $£ 32$ and their electricity had been cut off 4 months previously. The house was allelectric and they had a new baby. 'Mother now attending Family Doctor for nerves' reported the Woman Visitor. Baby's food, tea \& meals being cooked on Calor Gas stove this is dangerous although children are kept out of the kitchen when in use...' The RSSPCC's Woman Visitor set about liaising with the family's creditors, obtaining help from charities for food and a pram for the baby, and she held on to the rent book until the debt was cleared. The father returned to work and the electricity was eventually restored after the Society intervened with the utility company. Between October 1969 and February 1970, the Woman Visitor attended the family on a number of occasions at various times of the day, reporting on what she saw. Her case notes reveal the degree to which ideas about traditional gender roles informed the approach of this agency.

12/10/69 : Visited home about 5.30 pm Saw parents \& children being fed evening meal sausage and potatoes. Baby asleep not disturbed. Father to start work... Weekly rations seen in food cupboard, three candles burning in kitchen. House was clean and wash seen drying. Mother does a good clean wash...

5/2/70: Visited home about 12.30. Windows had been cleaned \& curtains washed. Beds examined and remade with Mother in good order. Instructions given for floors in children's bedrooms to be scrubbed for next visit... Rent Book seen. Book sealed ready for posting. Debt books seen paid weekly - Catalogues etc. call at the home. No money given for electricity as Mother has $£ 4$ left for food and debts. ${ }^{70}$

Through their observations about cleanliness, an orderly household and meal preparation this family was being judged by the standards of the male breadwinner-female homemaker model and in this case, because the family cooperated with the agency, they were provided with the help they needed to get back on their feet. This is a common pattern; women's and men's responsibilities were regarded through a traditional lens. Men were regarded as providers. Women were responsible for maintaining a clean and tidy home, for managing financially in spite of husbands who acted irresponsibly. It was not uncommon for the RSSPCC to advise a woman to meet her husband from work to take his wages off him before he drank or gambled them away and officers were not afraid to visit men at their place of work, presumably to humiliate them into supporting their families. ${ }^{71}$

Prescriptive assumptions regarding ideal gendered roles within the family shaped the agency's approach to 'problem families'. This is also clear from a number of other projects initiated by the RSSPCC, one of which was a Mothers' Group, established in 1973 and designed to educate women in the art of preparing meals using 'basic low cost foods which are rich in nutritional value, and at the same time, able to fill hungry bellies.' The project was deemed a success: 'The Woman Visitor has found that these mothers have gained confidence in the management of their own homes as a result of this Group and also more confidence in themselves. ${ }^{72}$ The Mothers' Group was an initiative that bears some comparison with Jephcott's efforts to empower the young mothers she encountered in the high flats. With her Settlement work background and her experience of researching young women's lives in London, she pursued an action research agenda in the interstices of the High Flats project designed to address the specific problems experienced by women with young children. Students associated with the High Flats project were directed to research the social isolation of this group, undertake a comparison of children living in high and low rise housing, and to study the provision of play facilities and playgroups. ${ }^{73}$ Her project to establish a pre-school playgroup with a group of mothers in 
Royston was the most interventionist attempt to address the structural and social problems she witnessed and is discussed in greater detail by Hazley et al in their contribution to this special issue. It is worth noting here that in her final project in Birmingham in 1973, Jephcott undertook a focused study investigating how far high flats suited families with young children. In this case, although she replicated the action research method of helping to set up a playgroup, this time she was able to work with the mothers for 18 months 'when continuing support was necessary to keep interest alive and give them some conception of the work involved in introducing provision of this kind. ${ }^{74} \mathrm{Her}$ conclusions were similar to those of the Glasgow study: high flats were not suitable for families with young children, quoting one disillusioned mother: 'Thinks the flat most unsatisfactory. Very fed up indeed. ${ }^{75}$

\section{Conclusions}

Moving to a high flat was often an exhilarating experience for families for whom home had formerly been overcrowded and substandard accommodation. The material benefits in terms of modern facilities were nearly always welcomed and the environment was conducive to modern privatised family life, but for many women a home in a high flat was isolating and when coupled with financial problems, bred dependence on external agencies and a loss of autonomy. Pearl Jephcott, a social researcher with an affinity for issues affecting women and children, understood the connection between housing environment and social and psychological wellbeing, a link that has been proven in studies since her pioneering work. ${ }^{76}$

The particular environment of the high flats in this period often made it difficult for women to remain close to kinship and friendship networks and - importantly - inhibited the formation of new ones. In a very different contemporaneous context - that of the new town - which offered a more socially advantaged population the opportunity to relocate and was initiated in Scotland at the same time as the high rise experiment - young mothers quickly made friends and established networks that enabled them to ameliorate the isolation of looking after young children and to take paid employment to contribute to the higher living costs. ${ }^{77}$ In the high rises, on the other hand, women either returned to their mothers for social interaction in the daytime or they suffered in silence. When financial crisis struck they had few resources to draw on and the solutions offered were dependent on women conforming to domestic ideals rather than enabling a degree of independence. This of course would have meant significant investment in the infrastructure of child care and family support to enable these women to fashion lives that were as modern as the flats they lived in. Jephcott understood the importance of fostering resilience amongst young mothers in particular but she regarded the high flat model of housing as a inhibitor of efforts to improve social contacts and self help.

High flats were a modern experiment designed, in part, to release Glasgow's working population from degrading housing and to help foster a personal sense of dignity in the city's citizens. But the buildings themselves - the exterior and interior design and the location of some - served to exacerbate the isolation of one group of tenants, mothers with young children. It is perhaps ironic that an approach to high density redevelopment of Glasgow, intended to retain population within the city rather than see people move out to new towns and suburbs, served to condemn many poor and working class women to a less dignified and expansive life than many others had elsewhere. When this set of circumstances is placed in the context of the post war welfare system which constructed women as dependants and an employment market that was still segregated by gender, they served to create the conditions in which women were denied the dignity that comes with independence. The buildings themselves, so often blamed for the failure of this housing experiment, do not tell the whole 
story. Pearl Jephcott was always sceptical about the ability of rehousing to high flats to improve the circumstances of women and children; her research in Glasgow appears to have confirmed her preconceptions.

\footnotetext{
${ }^{1}$ This work was supported by the Leverhulme Trust under Grant RPG-2014-014 Housing, Everyday Life and Wellbeing over the Long term, Glasgow c.1950-1975. The authors would also like to thank the John Robertson Bequest, University of Glasgow, for supporting research into the RSSPCC archive, Laura Paterson who collected some of the Homes in High Flats data and Children 1st who granted permission to consult the RSSPCC case files.
}

\section{${ }^{2}$ Pearl Jephcott with Hilary Robinson (1971) Homes in high flats . Some of the human problems involved in multi-storey housing (Edinburgh: Oliver \& Boyd). The original Joseph Rowntree funded research project was entitled: 'The social implications of domestic housing in high flats.' Hannah Gavron (1966) The captive wife (Harmondsworth Penguin); Hilda Jennings (1962) Societies in the making: A study of development and redevelopment within a county borough (London: Routledge \& Kegan Paul). \\ ${ }^{3}$ R. Smith (1974) 'Multi-dwelling building in Scotland 1750-1970: a study based on housing in the Clyde Valley', in A. Sutcliffe (ed.), Multi-Storey Living: the British Working-Class Experience (London), p.229.}

${ }^{4}$ The High Flats Study surveyed a 5\% sample of households in high flats across the city of Glasgow (c.1000 households). Subsequently Jephcott identified 5 estates for more focused study: Wyndford, Royston, Red Road, Albion and Castlemilk. Our revisiting of Jephcott's study has focused on four sites: two city centre locations, Hutchesontown in the Gorbals and the Wyndford estate in Maryhill, a peripheral location, Castlemilk, and Moss Heights which was an architect-designed site in Cardonald in the west of the city. All references to individual questionnaire respondents have been anonymised. University of Glasgow Archives (UGA): DC 127. Study of High Flats. Department of Economic and Social Research, University of Glasgow.

${ }^{5}$ Glasgow Caledonian University Archives (GCUA), GB 1847 RSSPCC: Children 1st Archive. Details of 6635 anonymised RSSPCC cases in the Strathclyde region c.1945-76. The RSSPCC became Children 1st in 1995.

${ }^{6}$ The High Flats study questionnaires collected a range of demographic, employment and residential information from households as well as asking for responses to the flat, the block and the estate and requesting views on facilities for children. Most interviews lasted no more than 30 minutes.

${ }^{7}$ See Judy Giles (2004) The parlour and the suburb: Domestic identities, modernity, class and gender (Oxford: Berg) Giles (1995) Women, identity and private life in Britain 1900-1950 (Basingstoke: Macmillan) both of which show how the home was conceived as coterminous with female identity in the period up to World War Two. On the postwar era see Graham Crow, 'The post-war development of the modern domestic ideal' in G.Allan and G.Crow (eds) (1989) Home and family: Creating the domestic sphere (Basingstoke: Palgrave Macmillan), pp.14-32. 
${ }^{8}$ Children aged 0-14 were underrepresented in high flats compared with their numbers in Glasgow's population - around $20 \%$ in the high flats, $27 \%$ in the census, though this still meant there were almost 7000 children under 15 in her sample alone. Jephcott's figures show that $27 \%$ of the 641 households in her main survey contained children and of those $27 \%$ contained a child under the age of 4 years. Jephcott, Homes in high flats, pp.46, 51, 81, 173.

${ }^{9}$ Scottish Screen Archive: 'Mungo's Medals'. Public Information film produced by Glasgow Corporation, 1961.The film can be viewed at http://movingimage.nls.uk

${ }^{10}$ Jephcott, Homes in High Flats, p.175; UGA, DC 127/1-10: Moss Heights questionnaires (20 households). The questionnaires are randomly stored in 10 boxes with no serial numbers.

${ }^{11}$ Jane Lewis (ed.) (1983) Women's welfare, women's rights (London: Croom Helm), pp. 3-4.

${ }^{12}$ Michael Young and Peter Willmott (1957) Family and kinship in East London (London: Penguin); Jennings, Societies in the making. For a recent critique see Ben Jones (2012) The working class in mid-twentieth century England (Manchester: Manchester University Press).

${ }^{13}$ Jennings, Societies in the Making, pp.52-4.

${ }^{14}$ In 1913 there were 44,354 one roomed houses in Glasgow. R.J.Morris, 'Urbanisation and Scotland' in W.H.Fraser and R.J.Morris (eds) (1990) People and society in Scotland. Volume II, 1830-1914 (Edinburgh: John Donald), p. 83.

${ }^{15}$ John Butt, 'Working-class housing in the Scottish cities 1900-1950' in G.Gordon and B.Dicks (eds) (1982) Scottish urban history (Aberdeen: Elsevier), p.234.

${ }^{16}$ This kind of social activity is widely referenced in popular culture from Edith Cowan's memoir of life in Glasgow Spring Remembered: a Scottish Jewish Childhood (1990) to the well known play 'The Steamie' set in Glasgow in the 1950s.

${ }^{17}$ Louise Christie (1993) Gender, design and ideology in council housing: urban Scotland 1917-1944, Planning History 15:3, pp.6-13, here 6; Lynn Abrams and Linda Fleming (2010) From scullery to conservatory: everyday life in the Scottish home', in Lynn Abrams and Callum.G.Brown (eds), A history of everyday life in twentieth century Scotland (Edinburgh: Edinburgh University Press), pp.4875 , here 61-2.

${ }^{18}$ There is no Scottish study to compare with those undertaken in England in the 1960s but for a discussion of a Glasgow working-class community in the 1970s see Sean Damer (1989) From Moorepark to 'Wine Alley': the rise and fall of a Glasgow housing scheme (Edinburgh: Edinburgh University Press). On sex roles in the Scottish family see Eleanor Gordon (1990), 'Women's Spheres' in Fraser and Morris, People and Society, p. 207; Arthur McIvor (1992) 'Women and Work in Twentieth Century Scotland', in A.Dickson and J.H.Treble (eds), People and Society in Scotland, Volume III, 1914-1990 (Edinburgh: Edinburgh University Press), p.143 and 151.

${ }^{19}$ Jennings, Societies in the making, p.106.

${ }^{20}$ Young and Willmott, Family and kinship, p. 140.

${ }^{21}$ Anna C.M. Robinson (2002) 'Children in Good Order': A study of the constructions of child protection in the work of the Royal Scottish Society for the Prevention of Cruelty to Children, in the West of Scotland, 1960-1989', University of Stirling doctoral thesis, pp.122-4.

${ }^{22}$ UGA, DC 127/13/3: The Herald 3 May 1969, 'Third of tenants want to leave scheme'. 
${ }^{23}$ Dr S.Taylor (1938) 'The suburban neurosis', The Lancet, 26 March, pp.759-61. Ali Haggett (2012) Desperate housewives, neuroses and the domestic environment 1945-1970 (London: Ashgate).

${ }^{24}$ Gavron, The Captive Wife, p. 99. In this respect Gavron's findings chimed with those of Willmott and Young amongst the Bethnal Green residents who moved to Greenleigh. 'I'm only interested in my own little family ... my life down here is my home', remarked one.

${ }^{25}$ Gavron, Captive Wife, p.111.

${ }^{26}$ Gavron, Captive Wife, p.135. See also Stella Lowry (1990) 'Families and Flats', British Medical Journal 300 (27 Jan), pp.245-7; and Brown and Harris's study The social origins of depression: a study of psychiatric disorder in women (1978) which cited an increased incidence of depression amongst working-class women owing to 'more severe life events' and difficulties with housing and finances. Cited in Haggett, Desperate Housewives, p. 109.

${ }^{27}$ The most notable exceptions were the Hutcheson blocks in the Gorbals designed by Sir Basil Spence and the Red Road flats designed by Glasgow Corporation architect Sam Bunton.

${ }^{28}$ Lynsey Hanley (2012), Estates: an intimate history (London: Granta), p.114.

${ }^{29}$ Alison Ravetz, 'A View from the interior' in Judy Attfield and Pat Kirkham (eds) (1995), A view from the interior: feminism, women and design (London: The Women's Press), pp. 202-3.

${ }^{30}$ UGA, DC127/1-10: Mrs M., Netherton Court (Castlemilk).

${ }^{31} 23$ per cent had no dislikes in respect of the house. The most frequent dislike (15\%) was that it was expensive to run or had a high rent . Jephcott, Homes in high flats, Table 22 p.177.

${ }^{32}$ Jephcott, Homes in high flats, Table 11, p.172. More than two thirds of respondents had lived in their high flat for 2 years or less.

${ }^{33}$ Jephcott, Homes in high flats, p. 110

${ }^{34}$ Glasgow Herald, 11 Aug. 1965.

${ }^{35}$ Communal electric drying cupboards were provided in many blocks operated by timed meters. See http://glasgowhousing.academicblogs.co.uk/washing-and-drying-clothes-in-high-flats/ (accessed 29.9.16).

${ }^{36}$ Jephcott, Homes in high flats, p.93.

${ }^{37} 36 \%$ of respondents in Jephcott's survey had moved less than a mile; 19\% 1-2 miles; 21\% 2-4 miles; 24\% 4 miles or more. Jephcott, Homes in high flats, p.171.

${ }^{38}$ UGA, DC 127/1-10: Mrs S., Waddel Court (Hutchesontown, Gorbals).

${ }^{39}$ For a summary of the Mitchellhill development at Castlemilk see

http://www.gla.ac.uk/schools/humanities/research/historyresearch/researchprojects/housingandwellbei ng/castlemilk/.

${ }^{40}$ UGA, DC 127/1-10: Mrs S., Castleton Court, Castlemilk. On the problems associated with bringing up young children in high flats see Joan Maizels (1961), Two to five in high flats: an enquiry into play provision for children living in high flats (London: Housing Centre). This mother's concerns about her child's development were mirrored by wider concerns that children's play and developmental needs 
were not adequately met in the high flats environment . It was said that high flats children were quieter and less curious than their peers. Jephcott, Homes in high Flats, p.96.

41 'Mungo's Medals', c.9m30s.

${ }^{42}$ UGA, DC 127/1-10: Mrs C H., Cathkin Court, Castlemilk.

${ }^{43}$ UGA, DC 127/1-10: Mrs W., Royston Rd.

${ }^{44}$ UGA, DC 127/1-10: Miss A., Kingsway Court, Scotstoun: Single women, full time work: Very satisfied. As long as they don't put up the rent and rates any more. Suits me very well and is enough to look after when I am out working all day. On the anonymity of high flat living see Jephcott, Homes in high flats pp.106-18.This example, Mr C., Crighton Court, Mitchell Hill Road (Castlemilk).

${ }^{45}$ Amongst women in Jephcott's study 401 out of 700 women 'in employment' were identified by occupation. The remaining 299 were listed as providing no information or unemployed, Homes in high flats, p.174.

${ }^{46}$ Willmott and Young, Family and Kinship, pp.149-53 and David Kynaston (2010) Family Britain 1951-57 (a new Jerusalem) (London: Bloomsbury), pp.?

${ }^{47}$ Ross McKibbin (1998), Classes and cultures: England 1918-1951 (Oxford: Oxford University Press), pp.190-1.

${ }^{48}$ Jephcott, Homes in high flats, p.107.

${ }^{49}$ UGA, DC127/13/5: Glasgow Chamber of Commerce Journal, August 1965, No.8. 'Social Conditions in High Flats'.

${ }^{50}$ Jephcott, Homes in high flats, p.175.

${ }^{51}$ Jephcott, Homes in high flats, pp. 66-7.

${ }^{52}$ Jephcott, Homes in high flats, p.93.

${ }^{53}$ UGA: DC 127/13/1, ethnographic description by Valerie Sommerville of estate layout and amenities of 'Castelmilk Flats',October 1967.

${ }^{54}$ UGA: DC 127/17/1, Notes made by Hilary Robinson - 2 week period of observation at Broomloan Court, Albion. On the discussion groups in Royston see Jephcott, Homes in high flats, p.98.

${ }^{55}$ UGA: DC 127/1-10: Mrs O’ D., Cranhill.

${ }^{56}$ D.M.Fanning (1967) 'Families in Flats', British Medical Journal 4, pp.382-6.

${ }^{57}$ Elizabeth Gittus (1976) Flats, families and the under fives (London: Routledge), pp. 104-7. The higher the flat the worse was the incidence. Gillis's study of Canada in 1977 also found that floor level was an indicative factor, especially for women because traditional sex roles confined women more to the home than men - 'it may be difficult for women who occupy a traditional wife-mother status to perform their roles in modern, man-made environments'. A. R. Gillis (1977), 'High-rise housing and psychological strain', Journal of Health and Social Behavior 18, pp.418-431.

${ }^{58}$ UGA, DC127/13/2: (Document 65): Letter to Pearl Jephcott from Medical Officer of Health (Dr Shore), Public Health Department, Aldridge, Staffordshire. Concerning Flats in Multi-Storey Blocks.

${ }^{59}$ Jephcott, Homes in high flats, p. 158 
${ }^{60}$ Jane Lewis (ed.), Women's Welfare, Women's Rights (London, 1983), pp. 3-4. This also had implications for tenancies of flats.

${ }^{61}$ Jephcott, Homes in high flats, pp.80-3.

${ }^{62} \mathrm{Jephcott}$, Homes in high flats, p.175.

${ }^{63}$ Abstract of Scottish Statistics

${ }^{64}$ UGA, DC127/1-10: Mr G., Moss Heights.

${ }^{65}$ The exception was Moss Heights which had gas until the Ronan Point gas explosion in London in 1968 prompted a change in policy.

${ }^{66}$ National Records of Scotland (NRS), GD 409/29/12: Report on Effect of Hire Purchase (Glasgow and Hamilton) 1963.

${ }^{67}$ Women Visitors were first employed by the RSSPCC in the 1950s. Robinson argues that it was not until the 1980s that the approach adopted towards families in trouble took on a 'feminist-welfare' character incorporating recognition of the rights of women. Prior to this the organisation's intervention had taken the form of warnings and material aid. Robinson, 'Children in Good Order', pp.6-7.

${ }^{68}$ NRS, GD 409/33/4: B.J.Ashley and H.Cohen (1972) Neglected Families known to the RSSPCC (Edinburgh: Moray House), pp.3 and 11. The number of cases analysed by this study was 475 . Minimum need was set at £7.1.0 for a married couple plus varying amounts between $£ 1.5 .0$ and $£ 2.18 .0$ for dependent children.

${ }^{69}$ Sue Innes and Linda McKie (2006) 'Doing what is right: researching Intimacy, Work and Family Life in Glasgow, 1945-1960', Sociological Research Online http://www.socresonline.org.uk/11/2/innes.html. Robinson, 'Children in Good Order', p.120.

${ }^{70}$ Glasgow Caledonian University Archives (GCUA), Children $1^{\text {st }}$ archive: RSSPCC case files, G1330A 1969-70.

${ }^{71}$ GCUA, Children $1^{\text {st }}$ archive, RSSPCC case files, case 74/6/5.

${ }^{72}$ NRS, GD 409/41/11: RSSPCC Newsletter c.1973 No.2

${ }^{73}$ UGA, DC127/15/4 1967: Hilda Brown, dissertation hypothesis: 'that mothers, with at least two children under school age, living in multi-storey blocks of flats are more socially isolated than similar mothers living in low rise housing'.

${ }^{74}$ Pearl Jephcott (1975) Young Families in High Flats (Birmingham Housing Department), p. 31.

${ }^{75}$ Ibid., p.9.

${ }^{76}$ Hugh .L. Freeman, (1984) Mental Health and the Environment (London: Churchill Livingstone); Ade Kearns, Elise Whitley, Phil Mason, Lyndal Bond (2011) "'Living the high life"? Residential, social and psychosocial outcomes for high-rise occupants in a deprived context', Housing Studies 30, pp.1-30.

${ }^{77}$ The new towns saw an increase in women's employment rates where light industry - by utilising part time and shift work - capitalised on women's need to earn to afford their new lifestyle and their changing aspirations in respect of widening their personal horizons beyond the home. In 1961 in East 
Kilbride 36 per cent of the female population was economically active (compared with a Scottish average of 32 per cent) and 82 per cent of those were married compared with just 47 per cent of employed women in Glasgow. Lynn Abrams and Linda Fleming (2011) 'Long term experiences of tenants in social housing in East Kilbride: an oral history study', http://eprints.gla.ac.uk/58439/ pp.1719. 